Tropical Journal of Pharmaceutical Research November 2015; 14 (11): 2023-2030

ISSN: $1596-5996$ (print); 1596-9827 (electronic)

(c) Pharmacotherapy Group, Faculty of Pharmacy, University of Benin, Benin City, 300001 Nigeria.

All rights reserved.

Available online at http://www.tjpr.org

Original Research Article

http://dx.doi.org/10.4314/tjpr.v14i11.11

\title{
Effects of Yifukang Oral Liquid on Chemotherapy- and Radiotherapy-Induced Toxic and Side Effects of Myelosuppression, Leucopenia and Gastrointestinal Tract Disturbances
}

\author{
Xi-Kui Tian, Hong-Di Lv1, Qing-Hua Zhao², Shao-Jun Hao, Xiu-Li Geng ${ }^{1}$, Xi- \\ Dong Wang ${ }^{1}$, Zheng-Chen Zhang ${ }^{1}$ and Jian-Chang Zhao ${ }^{1 *}$ \\ ${ }^{1}$ The 371 st Central Hospital of PLA, Xinxiang 453000, Henan, ${ }^{2}$ The Jinan Military Institute for Drug Control, Jinan 250000 , \\ Shandong, PR China
}

*For correspondence: Email: jczhao_2015@163.com

Received: 15 February 2015

Revised accepted: 7 October 2015

\begin{abstract}
Purpose: To investigate the effects of Yifukang oral liquid (YFKOL) on chemotherapy- and radiotherapy-induced myelosuppression, leucopenia and gastrointestinal tract disturbances.

Methods: The effects of YFKOL on myelosuppression, leucopenia and gastrointestinal tract disturbances were assessed by cyclophosphamide- and Co60-induced leucopenia in mice, copper sulfate-induced emesis in pigeons, ethanol-induced gastric mucosal lesions in rats, gastric emptying and intestinal propulsion in mice.

Results: In cyclophosphamide- and Co60-induced leucopenia assays, the mean white blood cell count (82.6 and $90.1 \times 10^{9} / \mathrm{L} ; 7.3$ and $8.2 \times 10^{9} / \mathrm{L}$, respectively) and thighbone marrow granulocytes $(66.1 \%$ and $67.4 \% ; 60.8$ and $66.5 \%$, respectively) were significantly $(p<0.05)$ increased after treatment with YFKOL (15 and $30 \mathrm{~mL} / \mathrm{kg})$, compared with the respective control $\left(68.2\right.$ and $4.7 \times 10^{9} / \mathrm{L} ; 58.2$ and 53.1 $\%)$. In emesis, gastric mucosal lesions, gastric emptying and intestinal propulsion assays, the mean frequency of emesis (30.8 and 22.3 times, respectively) and ulcer index (39.6 and 26.5, respectively) significantly $(p<0.05)$ decreased, and the mean gastric emptying $(25.0$ and $24.0 \%)$ and intestinal propulsion (81.9 and $82.8 \%)$ were significantly $(p<0.05)$ promoted after treatment with YFKOL $(10$ and $20 \mathrm{~mL} / \mathrm{kg}$ ), compared with the respective control (54.7 times, 62.8, 42.0 and $68.9 \%$ ).

Conclusion: YFKOL may suppress chemotherapy- and radiotherapy-induced myelosuppression, leucopenia and gastrointestinal tract disturbances.
\end{abstract}

Keywords: Yifukang oral liquid, Gastrointestinal tract disturbances, Leucopenia, Myelosuppression, Tumor, Chemotherapy, Radiotherapy

Tropical Journal of Pharmaceutical Research is indexed by Science Citation Index (SciSearch), Scopus, International Pharmaceutical Abstract, Chemical Abstracts, Embase, Index Copernicus, EBSCO, African Index Medicus, JournalSeek, Journal Citation Reports/Science Edition, Directory of Open Access Journals (DOAJ), African Journal Online, Bioline International, Open-J-Gate and Pharmacy Abstracts

\section{INTRODUCTION}

Currently, malignant tumor is the leading cause of death in human, and middle-late malignant tumor can cause the symptoms of anepithymia, muscle weakness, weight loss, hypoimmunity, pain, etc [1], which will become more obvious with the development of tumor. Chemotherapy and radiotherapy, the usual methods for treating tumor [2-5], does not only exacerbate the above symptoms, but also induce many toxic and side effects, such as myelosuppression, leucopenia, emesis and nausea [6-8]. 
Based on the knowledge of traditional Chinese medicine, a prescription named Yifukang oral liquid (YFKOL) was developed by our team to suppress the symptoms of myelosuppression, leucopenia and gastrointestinal tract disturbances induced by chemotherapy and radiotherapy. YFKOL is composed of 6 kinds of Chinese medicines including Ginseng Radix et Rhizoma (200 g), Pangolin Scales (100 g), Angelicae Sinensis Radix (150 g), Astragali Complanati Semen (300 g), Scrophulariae Radix $(200 \mathrm{~g})$ and Ophiopogonis Radix (200 g).

The objective of this study was to investigate the effects of YFKOL on chemotherapy- and radiotherapy-induced myelosuppression, leucopenia and gastrointestinal tract disturbances were assessed by cyclophosphamide- and Co60-induced leucopenia models in mice, copper sulfateinduced emesis model in pigeons, ethanolinduced gastric mucosal lesions model in rats, using gastric emptying and intestinal propulsion assays in mice.

\section{EXPERIMENTAL}

\section{Plant materials}

Ginseng Radix et Rhizoma, Pangolin Scales, Angelicae Sinensis Radix, Astragali Complanati Semen, Scrophulariae Radix and Ophiopogonis Radix were obtained from Beijing TongRenTang, Co, Ltd and the plant materials were identified by Shao-Jun Hao, a taxonomist, the 371st Central Hospital of PLA's Pharmacy Department, Xinxiang Henan, China. A series of voucher specimen (voucher no. 201381/CPLA371, 201382/CPLA371, 201383/CPLA371, 201384/CPLA371, 201385/CPLA371 and 201386/CPLA371) was stored in dispensary of traditional Chinese medicine of our hospital for future reference.

\section{Chemicals and reagents}

Cyclophosphamide was purchased from the 12th Shanghai pharmaceutical factory (batch number: 080330). Copper sulfate was obtained from Zhengzhou chemical reagent first factory (batch number: 920429). Methyl orange was purchased from Shanghai reagent third factory (batch number: 930924). Fu Fang E Jiao Jiang (FFEJJ) was purchased from Shan Dong Dong-E E-Jiao Co., Ltd (batch number: 080112). Oulishu oral liquid (OLSOL) was obtained from Xinxiang yuanda pharmaceutical factory in China (batch number: 960607).

\section{Preparation of YFKOL}

YFKOL was provided by the 371st Central Hospital of PLA's manufacturing laboratory (batch number: 970203). The preparation of YFKOL was described as follows. Ginseng Radix et Rhizoma (200 g), Pangolin Scales (100 g), Angelicae Sinensis Radix (150 g), Astragali Complanati Semen (300 g), Scrophulariae Radix $(200 \mathrm{~g})$ and Ophiopogonis Radix (200 g) were decocted with water for $40 \mathrm{~min}$ for three times. The combined decoction filtrate was concentrated to reach a relative density of 1.15 $1.30\left(80{ }^{\circ} \mathrm{C}\right)$, then concentrate was diluted by ethanol to obtain $60 \%$ ethanol solution followed by standing at room temperature for $24 \mathrm{~h}$. After filtration, the obtained ethanol solution was condensed to remove alcohol, and simple syrup was added into the solution. The above solution was diluted by water to get $1000 \mathrm{~mL}(\mathrm{pH}=5.0$ 7.0) solution which was filtrated and sterilized to gain YFKOL.

\section{Animals}

All animal treatments in this study were in accordance with the National Institute of Health Guide for the Care and Use of Laboratory Animals [9] and experiments were approved by the ethics committee of the 371st Central Hospital of PLA (protocol no. PLA $371 \mathrm{CH} 2013$ ). In this research, a lot of measures were performed to reduce the amount of animals and relieve the suffering of animals. Male and female pigeons $(300-450 \mathrm{~g})$, SD rats $(200 \pm 20 \mathrm{~g})$ and ICR mice (20 $\pm 2 \mathrm{~g})$ were provided by Henan medical university laboratory animal center. Animals were bred with constant room temperature $\left(25{ }^{\circ} \mathrm{C}\right)$ and appropriate humidity (55 $-60 \%$ ). Animals had free access to food and water.

\section{Acute toxicity study of YFKOL}

The result of acute toxicity studies of YFKOL showed that maximum tolerated dose (MTD) of YFKOL was more than $0.03 \mathrm{~mL} / \mathrm{g}$, which was far more than the maximum clinical dosage of YFKOL.

\section{Cyclophosphamide-induced leucopenia assay}

ICR mice were randomly divided into normal, control, YFKOL (high and low dose) and FFEJJ groups $(n=10)$. Control, YFKOL (high and low dose) and FFEJJ groups were treated with 80 $\mathrm{mg} / \mathrm{kg}$ cyclophosphamide once a day (3 days) by intraperitoneal injection (ip) and normal group was treated with isopyknic normal saline once a 
day (3 days) by ip. Meanwhile, control, YFKOL (high and low dose) and FFEJJ groups were separately treated with normal saline, YFKOL (30 and $15 \mathrm{~mL} / \mathrm{kg})$ and FFEJJ $(30 \mathrm{~mL} / \mathrm{kg})$ once a day (7 days) by intragastric administration (ig) and normal group was treated with isopyknic normal saline once a day (7 days) by ig. Finally, mice were directly sacrificed to obtain orbital blood and thighbone marrow after $2 \mathrm{~h}$ of drugs treatment on the seventh day. Orbital blood was used to determine white blood cell count according to the existed method [10]. Thighbone marrow smears, which were stained by Wright's stain, were monitored by a microscope. Thighbone marrow granulocytes percentage was used to evaluate the effect of drugs on cyclophosphamide-induced leucopenia [11].

\section{Co60-induced leucopenia assay}

In this assay, all groups' treatments and tests were the same as cyclophosphamide-induced leucopenia assay except that the modeling for control, YFKOL (high and low dose) and FFEJJ groups were induced by Co60.

\section{Copper sulfate-induced emesis assay}

Pigeons were randomly divided into control, YFKOL (high and low dose) and OLSOL groups $(n=10)$. Control, YFKOL (high and low doses) and OLSOL groups were separately treated with normal saline, YFKOL (20 and $10 \mathrm{~mL} / \mathrm{kg}$ ) and OLSOL $(8 \mathrm{~mL} / \mathrm{kg}$ ) once a day (3 days) by ig. Then, copper sulfate was administered orally to pigeons of control, YFKOL (high and low dose) and OLSOL groups at a dose of $300 \mathrm{mg} / \mathrm{kg}$ after $0.5 \mathrm{~h}$ of drugs treatment on the third day. Finally, the effects of drugs on copper sulfate-induced emesis were analyzed by incubation period and number of emesis within $1 \mathrm{~h}$.

\section{Ethanol-induced gastric mucosal lesions assay}

SD rats were randomly divided into control, YFKOL (high and low dose) and OLSOL groups $(n=10)$. The treatments of all groups were the same as copper sulfate-induced emesis assay. All rats were managed with abrosia, but had free access to water for $12 \mathrm{~h}$ on the third day. $75 \%$ ethanol $(0.8 \mathrm{~mL})$ was administered orally to each rat after $1.5 \mathrm{~h}$ of drugs treatment on the third day. After another one hour, mice were directly sacrificed for gathering stomach, which was then fixed by $1 \%$ formaldehyde for $30 \mathrm{~min}$. The situation of gastric mucosal lesions was directly observed. Based on gastric mucosal lesions area $\left(\mathrm{mm}^{2}\right)$, ulcer index was calculated according to existing method [12]. Damage inhibition rate, calculated as in Eq 1, and ulcer index was used to evaluate the effect of drugs on $75 \%$ ethanolinduced gastric mucosal lesions [13].

Damage inhibition rate $(\%)=\{(\mathrm{A}-\mathrm{B}) / \mathrm{A}\} 100 \ldots \ldots . .(1)$

Where $A$ and $B$ stands for the ulcer index of control group and treatment group, respectively.

\section{Gastric emptying assay}

ICR mice were randomly divided into control, YFKOL (high and low dose) and OLSOL groups $(n=10)$. The treatments of all groups were the same as copper sulfate-induced emesis assay. All mice were managed with abrosia, but had free access to water for $12 \mathrm{~h}$ on the third day. Methyl orange aqueous solution $(0.1 \%, 0.2 \mathrm{~mL})$ was administered orally to each mouse after $1 \mathrm{~h}$ of drugs treatment on the third day. Then, mice were directly sacrificed for gathering the stomach after 20 min of methyl orange aqueous solution treatment. Gastric content was washed into test tube by $10 \mathrm{~mL}$ distilled water, and the $\mathrm{pH}$ of above solution was adjusted to $6.0-6.5$ by $5 \%$ sodium bicarbonate. After filtration, the filtrate was analyzed by spectrophotometer at $420 \mathrm{~nm}$. The gastric residual rate of methyl orange, used to evaluate the effect of drugs on gastric emptying, was calculated as in Eq 2 [14].

$G(\%)=(C / D) 100$

where $C$ and $D$ stands for the optical density (OD) of methyl orange in stomach and methyl orange aqueous solution $(0.1 \%, 0.2 \mathrm{~mL})$, dilute by $10 \mathrm{~mL}$ distilled water, respectively.

\section{Intestinal propulsion assay}

ICR mice were randomly divided into control, YFKOL (high and low dose) and OLSOL groups $(n=10)$. The treatments of all groups were the same as copper sulfate-induced emesis assay. All mice were managed with abrosia, but had free access to water for $12 \mathrm{~h}$ on the third day. Carbon powder suspension composed of $10 \%$ arabic gum and $5 \%$ active carbon $(0.2 \mathrm{~mL})$ was administered orally to each mouse after $1 \mathrm{~h}$ of drugs treatment on the third day. Then mice were directly sacrificed for gathering total gastrointestinal tract after $20 \mathrm{~min}$ of carbon powder suspension treatment. The distance between pylorus and ileocecum (E), and between pylorus and carbon powder forefront $(F)$ were determined. Further, the propulsive rate of carbon powder, calculated as in Eq 3, was used to evaluate the effect of drugs on intestinal propulsion. 
Propulsive rate $(\%)=\{(E-F) / E\} 100$

\section{Statistical analysis}

All data are presented as mean \pm standard deviation $(S D, n=10)$ and were analyzed by one-way ANOVA of Statistical Package and Social Sciences (SPSS), version 21.0. $P<0.05$ was considered statistically significant.

\section{RESULTS}

\section{Effects of YFKOL on cyclophosphamide- induced leucopenia in mice}

The effects of YFKOL and FFEJJ on cyclophosphamide-induced leucopenia are shown in Figures 1 and 2 separately. After treatment with cyclophosphamide, the white blood cell count and thighbone marrow granulocytes percentage of control group significantly $(p<0.05$ or 0.01$)$ were inhibited, compared with normal group, which indicated the modeling was successful. The results shows that YFKOL (15 and $30 \mathrm{~mL} / \mathrm{kg}$ ) and FFEJJ $(30 \mathrm{~mL} / \mathrm{kg}$ ) significantly $(p<0.05$ or 0.01$)$ increased the white blood cell count and thighbone marrow granulocytes percentage, compared with control group.

\section{Effect of YFKOL on Co60-induced leucopenia in mice}

After treatment with Co60, the white blood cell count and thighbone marrow granulocytes percentage of control group were significantly ( $p$ $<0.05$ or 0.01 ) inhibited, compared with normal group, which indicated the modeling was successful. The effects of YFKOL (15 and 30 $\mathrm{mL} / \mathrm{kg})$ and FFEJJ $(30 \mathrm{~mL} / \mathrm{kg})$ on Co60-induced leucopenia indicated that they significantly $(p<$ 0.05 or 0.01 ) increased the white blood cell count and thighbone marrow granulocytes percentage,

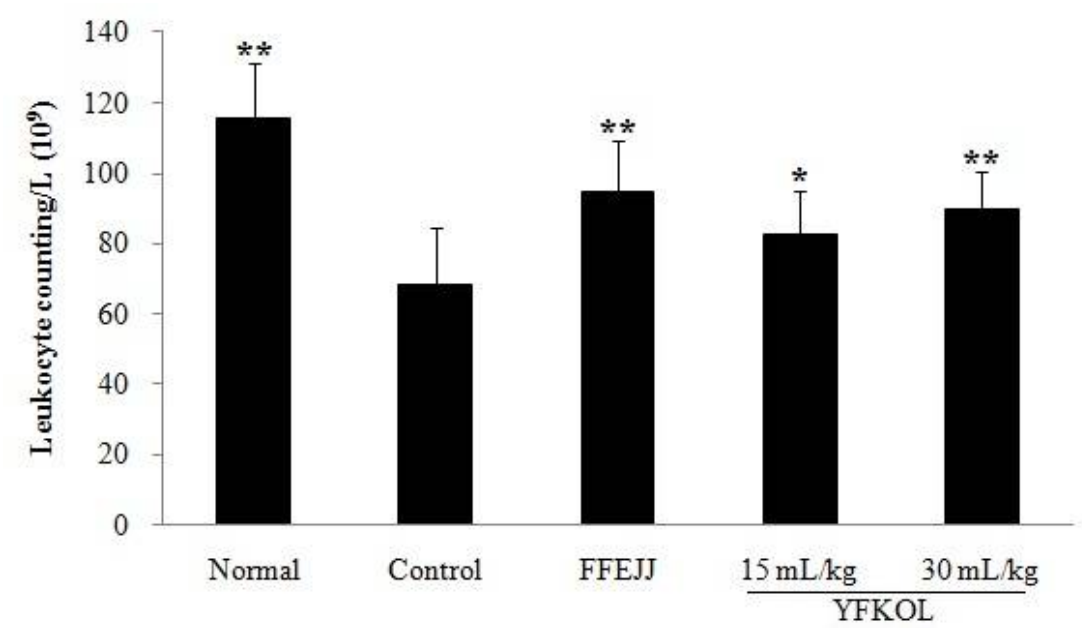

Figure 1: Effects of YFKOL and FFEJJ on cyclophosphamide-induced leucopenia model in ICR mice $(\mathrm{n}=10) ;{ }^{*} p$ $<0.05,{ }^{* *} p<0.01$, compared with control group

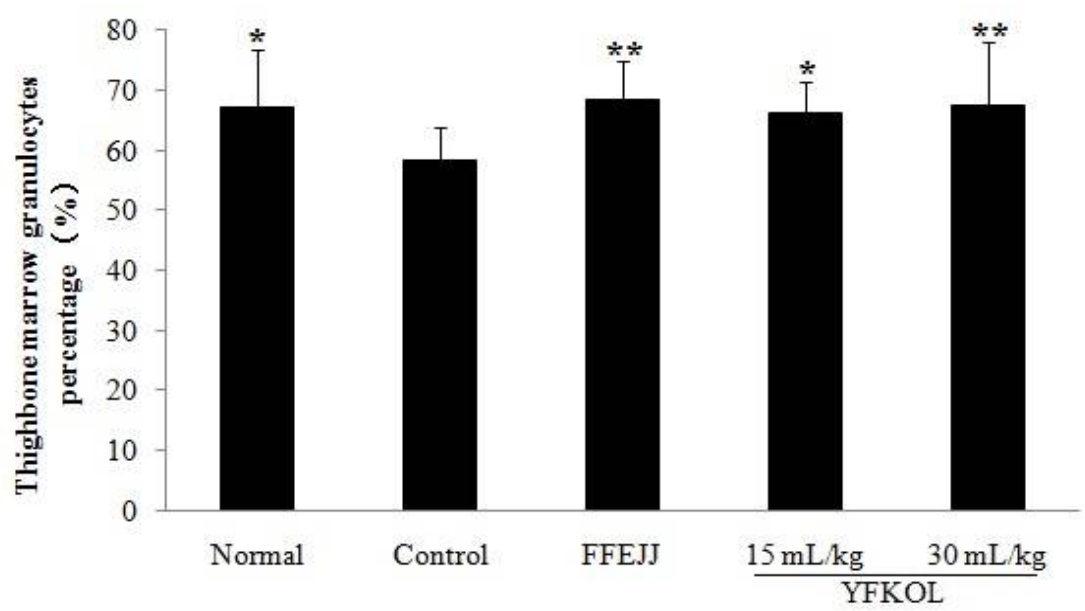

Figure 2: Effects of YFKOL and FFEJJ on thighbone marrow granulocytes of cyclophosphamide-induced leucopenia model in ICR mice $(n=10) ;{ }^{*} p<0.05$, ${ }^{* *} p<0.01$, compared with control group 
compared with control group, except that YFKOL $(15 \mathrm{~mL} / \mathrm{kg})$ cannot raise thighbone marrow granulocytes percentage. The results are depicted in Figures 3 and 4.

\section{Effects of YFKOL on copper sulfate-induced emesis in pigeons}

The results (Table 1) indicate that YFKOL (10 and $20 \mathrm{~mL} / \mathrm{kg})$ and OLSOL $(8 \mathrm{~mL} / \mathrm{kg})$ significantly $(p<0.05$ or 0.01$)$ decreased the number of emesis induced by copper sulfate within $1 \mathrm{~h}$, compared with control group. Moreover, YFKOL $(20 \mathrm{~mL} / \mathrm{kg})$ significantly $(p<$ 0.05 ) inhibited incubation period of emesis induced by copper sulfate, compared with control group.

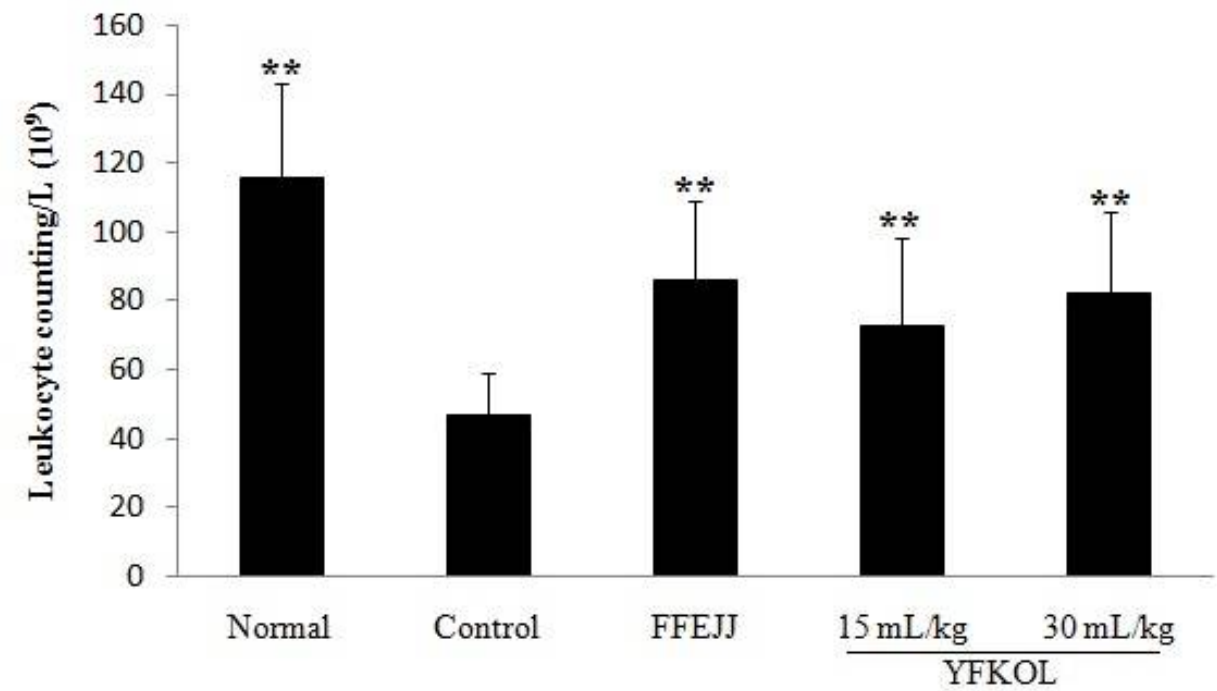

Figure 3: Effects of YFKOL and FFEJJ on Co60-induced leucopenia model in ICR mice $(\mathrm{n}=10) ;{ }^{*} p<0.05,{ }^{* *} p<$ 0.01 , compared with control group

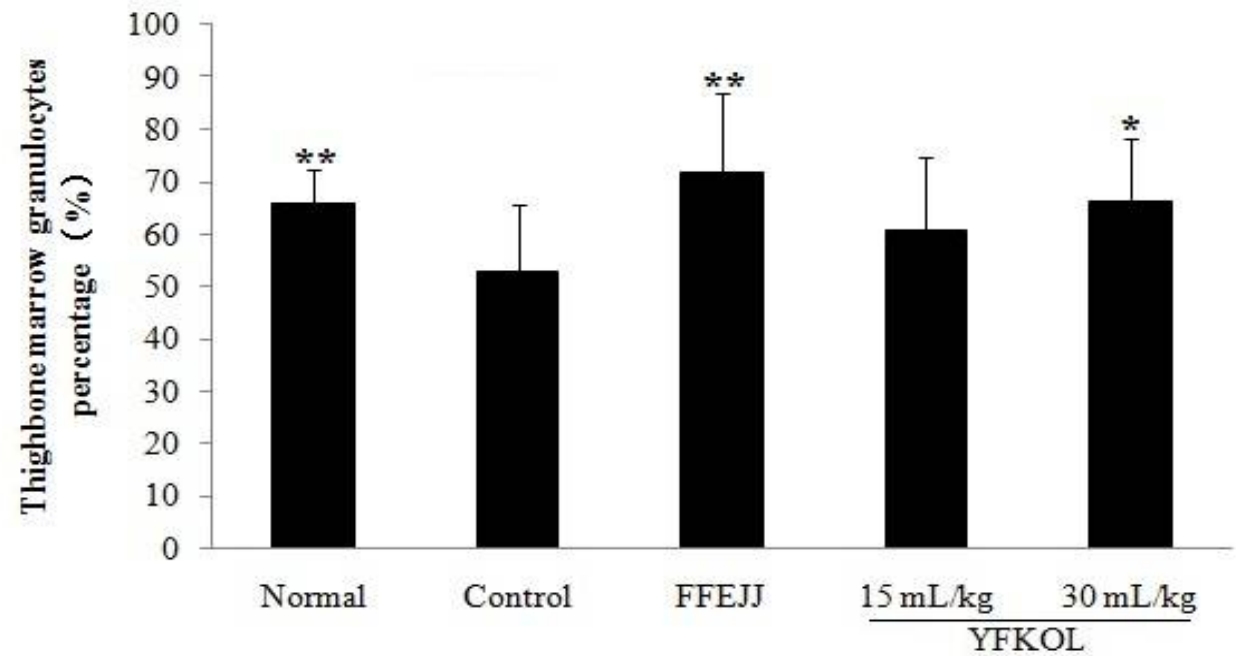

Figure 4: Effects of YFKOL and FFEJJ on thighbone marrow granulocytes of Co60-induced leucopenia model in ICR mice $(\mathrm{n}=10) ;{ }^{*} p<0.05,{ }^{* *} p<0.01$, compared with control group

Table 1: Effect of YFKOL on copper sulfate-induced emesis model

\begin{tabular}{lccc}
\hline Group & Dose $\mathbf{( m L / k g )}$ & Incubation period of emesis $(\mathbf{m i n})$ & Number of emesis $($ time/h) \\
\hline Control & & $16.4 \pm 5.2$ & $54.7 \pm 28.9$ \\
OLSOL & 8 & $18.0 \pm 6.9$ & $27.4 \pm 14.4^{*}$ \\
YFKOL & 10 & $19.5 \pm 8.1$ & $30.8 \pm 14.7^{*}$ \\
YFKOL & 20 & $26.2 \pm 10.5^{*}$ & $22.3 \pm 13.0^{* *}$ \\
\hline
\end{tabular}

All data stood for mean \pm standard deviation $(n=10) ;{ }^{*} p<0.05,{ }^{* *} p<0.01$ compared with control group 


\section{Effect of YFKOL on $75 \%$ ethanol-induced gastric mucosal lesions in rats}

The results (Table 2) indicated that YFKOL (10 and $20 \mathrm{~mL} / \mathrm{kg})$ and OLSOL $(8 \mathrm{~mL} / \mathrm{kg})$ significantly $(p<0.01)$ decreased ulcer index induced by $75 \%$ ethanol, compared with control group. Furthermore, the damage inhibition rate (\%) of OLSOL, $10 \mathrm{~mL} / \mathrm{kg}$ YFKOL and $20 \mathrm{~mL} / \mathrm{kg}$ YFKOL were $28.7,36.9$ and 57.8 separately.

\section{Effect of YFKOL on gastric emptying and intestinal propulsion in mice}

The results (Table 3 ) indicated that YFKOL (10 and $20 \mathrm{~mL} / \mathrm{kg})$ and OLSOL $(8 \mathrm{~mL} / \mathrm{kg})$ significantly $(p<0.05$ or 0.01$)$ decreased gastric residual rate of methyl orange and improved intestinal propulsion, compared with control group.

\section{DISCUSSION}

Based on the clinical observation, myelosuppression, leucopenia and gastrointestinal tract disturbances are the usual toxic and side effects of cancer chemotherapy and radiotherapy, which do great damage to immune system and digestive system of patients [15-17]. Thus, reducing these toxic and side effects were vital in the treatment of cancer. According to the knowledge of traditional Chinese medicine, YFKOL was developed to reduce chemotherapy- and radiotherapy-induced toxic and side effects of myelosuppression, leucopenia and gastrointestinal tract disturbances.

Cyclophosphamide-based chemotherapy and Co60-based radiotherapy are extensively used to treat tumor in clinic $[18,19]$. Thus, cyclophosphamide and Co60 were used to induce leucopenia in this research [20]. Similarly, FFEJJ and OLSOL were selected as positive control in this study [21-23].

The cyclophosphamide-induced and Co60induced leucopenia models in mice are two common methods used to study the therapeutic effects of drugs on leucopenia [24,25]. In this work, the two models were used to study the immune-enhancement effects of YFKOL. As depicted in Figures 1 - 4, chemotherapy- and radiotherapy-induced toxic and side effects of myelosuppression and leucopenia can be significantly decreased by YFKOL through increasing white blood cell count and thighbone marrow granulocytes percentage.

The copper sulfate-induced emesis model in pigeon and ethanol-induced gastric mucosal lesions model in rat are commonly used to explore the effects of drugs on emesis and gastric mucosal lesions [26,27]. In this work, the two models were used to study the effects of YFKOL on emesis and gastric mucosal lesions. As shown in Tables 1 and 2, YFKOL can significantly inhibit copper sulfate-induced emesis and ethanol-induced gastric mucosal lesions by decreasing the number of emesis and damage to gastric mucosa.

The gastric emptying and intestinal propulsion assays in mice are commonly used to study the effects of drugs on gastric emptying and intestinal propulsion functions [28]. In this research, the two assays were performed to study the effects of YFKOL on gastric functions. As shown in Table 3, YFKOL can significantly improve gastric functions by promoting gastric emptying and intestinal propulsion.

Table 2: Effect of YFKOL on $75 \%$ ethanol-induced gastric mucosal lesions model

\begin{tabular}{lccc}
\hline Group & Dose $(\mathbf{m L} / \mathbf{k g})$ & Ulcer index & Damage inhibition rate (\%) \\
\hline Control & & $62.8 \pm 13.4$ & \\
OLSOL & 8 & $44.8 \pm 11.8^{\star *}$ & 28.7 \\
YFKOL & 10 & $39.6 \pm 11.5^{\star *}$ & 36.9 \\
YFKOL & 20 & $26.5 \pm 9.0^{\star *}$ & 57.8 \\
\hline
\end{tabular}

All data stood for mean \pm standard deviation $(n=10)$. ${ }^{* *} p<0.01$, compared with control group

Table 3: Effect of YFKOL on gastric emptying and intestinal propulsion

\begin{tabular}{lccc}
\hline Group & Dose $(\mathbf{m L} / \mathbf{k g})$ & Methyl orange residual rate $(\%)$ & Propulsive rate (\%) \\
\hline Control & & $42.0 \pm 10.0$ & $68.9 \pm 9.8$ \\
OLSOL & 8 & $28.0 \pm 8.0^{\star *}$ & $77.3 \pm 5.8^{*}$ \\
YFKOL & 10 & $25.0 \pm 7.0^{* \star}$ & $81.9 \pm 16.2^{* *}$ \\
YFKOL & 20 & $24.0 \pm 10.0^{* *}$ & $82.8 \pm 7.2^{\star *}$ \\
\hline
\end{tabular}

All data stood for mean \pm standard deviation $(n=10) ;{ }^{*} p<0.05,{ }^{* *} p<0.01$, compared with control group 


\section{CONCLUSION}

YFKOL suppresses symptoms of myelosuppression, leucopenia and gastrointestinal tract, induced by chemotherapy and radiotherapy, by increasing white blood cell count and thighbone marrow granulocytes percentage, minimizing emesis and damage to gastric mucosa, and promoting gastric emptying and intestinal propulsion in animal models. This study may lead to another approach to tackling the toxic and side effects of myelosuppression, leucopenia and gastrointestinal tract disturbances induced by chemotherapy and radiotherapy. Thus, YFKOL may be used to help cancer patients to go through the undesirable effects of chemotherapy and radiotherapy, and therefore further efforst are required to investigate YFKOL in this regard.

\section{REFERENCES}

1. Parkin M, Bray F, Ferlay J, Pisani P. Global cancer statistics, 2002. CA Cancer J Clin 2005; 55: 74-108.

2. Seo YS, Kim JN, Keum B, Park S, Kwon YD, Kim YS, Jeen $Y T$, Chun HJ, Kim CY, Kim CD, et al. Radiotherapy for 65 patients with advanced unresectable hepatocellular carcinoma. World J Gastroenterol 2008; 14(15): 2394-2400.

3. Dawson LA, Eccles C, Bissonnette JP, Brock KK. Accuracy of daily image guidance for hypofractionated liver radiotherapy with active breathing control. Int J Radiat Oncol Biol Phys 2005; 62(4): 1247-1252.

4. Konno T. Targeting chemotherapy for hepatoma: arterial administration of anticancer drugs dissolved in Lipiodol. Eur J Cancer 1992; 28(2-3): 403-409.

5. Sridhar T, Symonds RP. Principles of chemotherapy and radiotherapy. Obstet Gynaecol \& Reprod Med 2009; 19(3): 61-67.

6. Kim YS, Sun JM, Ahn JS, Ahn MJ, Park K. The optimal duration of vitamin supplementation prior to the first dose of pemetrexed in patients with non-small-cell lung cancer. Lung Cancer 2013; 81(2): 231-235.

7. Abali $H$, Celik L. Tropisetron, ondansetron, and granisetron for control of chemotherapy-induced emesis in Turkish cancer patients: a comparison of efficacy, side-effect profile, and cost. Cancer Invest 2007; 25(3): 135-139.

8. Roila F, Herrstedt J, Aapro M, Gralla RJ, Einhorn LH, Ballatori E, Bria E, Clark-Snow RA, Espersen BT, Feyer $P$, et al. Guideline update for MASCC and ESMO in the prevention of chemotherapy- and radiotherapy-induced nausea and vomiting: results of the Perugia consensus conference. Ann Oncol 2010; 21(Supp/ 5): v232-v243.

9. CPCSEA guidelines for laboratory animal facility. Indian $J$ Pharmacol 2003; 35: 257-274.
10. Xu SY, Bian RL, Chen $X$. Methodology of pharmacological experiment. Beijing: People's Medical Publishing House; 2002. 1248 p.

11. Wang HP, Zhao XX, Tian KY. Dynamic changes of leukocyte and myelogram in the rat leucopenia model. J Zhenzhou Univ (Med Sci) 2002; 37(4): 439440.

12. Guth PH, Aures D, Paulsen G. Topical aspirin plus $\mathrm{HCl}$ gastric lesions in the rat. Gastroenterology 1979; 76(1): 88-93.

13. Li B, Liu HR, Pan YQ, Jiang QS, Shang JC, Wan XH, He $B C$, Yang JQ, Zhou $Q X$. Protective effect of total alkaloids from rhizome Coptis chinensis on alcoholinduced gastric lesion in rats. Chin J Chin Mater Med 2006; 31(1): 51-54.

14. Ge X, Guan QH, Jian FW, Li R, Wang DM. Experimental investigation of Jianwei grain on gastric emptying and intestinal propulsion. J Dalian Med Univ 2003; 25(3): 183-184.

15. Gu JF. 51 cases of patients with lung cancer during chemotherapy and radiotherapy nursing. J Clin Med Pract 2011; 15(2): 5-6.

16. Ma XL, Li J. Prevention and treatment clinical marrow after chemotherapy leucopenia yangyin fill for 58 case. Chin Med Modern Distance Education of Chin 2014; 12(10): 32-33.

17. Liu L, Jiang T, Li DJ. Disscussion on Chinese herbal medicines in treatment of gastrointestinal reactions caused by cancer chemotherapy. Global Tard Chin Med 2014; 7(9): 737-740.

18. Chi SP, Bai BK, Xie J, Chen HG, Du L, You LY, Cheng Y. Study of the effect and mechanism of Cyclophosphamide on antitumor in animal model. Chin Med Herald 2012; 9(14): 20-22.

19. Andero P, Wulff J, Burns DT, Palmans H. Consistency in reference radiotherapy dosimetry: resolution of an apparent conundrum when (60)Co is the reference quality for changed-particle and photon beams. Phys Med Biol 2013; 58(19): 6593-6621.

20. Miao MS. Experimental animals and animal experimental technology. Beijing: Chinese Medicine Press; 1997. $243 p$.

21. Chen HH, You JH, Tian SS, Zhang Y, Feng MJ. Overview of pharmacological and clinical study on compound Ejiao Jiang. China J Chin Mater Med 2012; 37(20): 3021-3023.

22. Miao MS, Zhou LH, Hou JH, Chen GL, Zhang YL. Influences of four kinds of Chinese medicines that can relieve marrow restraint after chemotherapy on peripheral blood and bone marrow smear in model of hematopenia induced by cyclophosphamide. J Clin Rehabilitative Tissue Eng Res 2007; 11(20): 39984000.

23. Hong $X H, Y u W L$, Wei CE, Li LD. Study on primary pharmacodynamic of Oulishu oral liquid. Trad Chin Drug Res Clin Pharmacol 1995; 6(3): 19-21.

24. Soeda M, Ome M, Otomo M. Studies on therapeutic effect of solcoseryl on leucopenia by Co60 or X ray

Trop J Pharm Res, November 2015; 14(11): 2029 
irradiation. Nihon lqaku Hoshasen Gakkai Zasshi 1965; 25(2): 151-155.

25. Huang GC, Wu LS, Chen LG, Yang LL, Wang CC. Immuno-enhancement effects of Huang Qi Liu Yi Tang in a murine model of cyclophosphamideinduced leucopenia. J Ethnopharmacol 2007; 109(2): 229-235.

26. Feng Y, He QS, Liu W, Zhang YL, Meng QH. Affection of Xiao Banxia plus Fuling grain on MTL in CINV piget plasma. J Liaoning Univ TCM 2009; 11(1): 175-177.
27. La Casa C, Villegas I, Alarcon de la Lastra C, Motilva V, Martin Calero MJ. Evidence for protective and antioxidant properties of rutin, a natural flavone, against ethanol induced gastric lesions. $J$ Ethnopharmacol 2000; 71(1-2): 45-53.

28. Li Y, Chen SN, Li YQ, Xu BY, Tashiro SI. Effect of each component of Shao-Yao-Gan-Cao-Tang and Si-NiSan on gastric emptying and small intestinal propulsive functions. Chin J Dig 1996; 16(1): 18-21. 